\title{
Lack of Disease Specificity Limits the Usefulness of In Vitro Costimulation in HIV- and HCV-Infected Patients
}

\author{
Stefanie Kuerten, ${ }^{1,2}$ Tobias R. Schlingmann, ${ }^{2}$ Tarvo Rajasalu, ${ }^{2}$ Doychin N. Angelov, ${ }^{1}$ \\ Paul V. Lehmann, ${ }^{2}$ and Magdalena Tary-Lehmann ${ }^{2}$ \\ ${ }^{1}$ Institut für Anatomie I, Medizinische Fakultät der Universität zu Köln, Joseph-Stelzmann-Str. 9, 50931 Köln, Germany \\ ${ }^{2}$ Department of Pathology, Case Western Reserve University, Wolstein Building, 10900 Euclid Avenue, Cleveland, OH 44106, USA
}

Correspondence should be addressed to Stefanie Kuerten, skuerten@smail.uni-koeln.de

Received 2 April 2008; Accepted 23 June 2008

Recommended by Mario Clerici

Measurements of antigen-specific T cell responses in chronic diseases are limited by low frequencies of antigen-specific cells in the peripheral blood. Therefore, attempts have been made to add costimulatory molecules such as anti-CD28 or IL-7/IL15 to ELISPOT assays to increase sensitivity. While this approach has been successful under certain circumstances, results are often inconsistent. To date, there are no comprehensive studies directly comparing the in vitro effects of multiple costimulatory molecules in different disease settings. Therefore, in the present study we tested the effects of IL-7/IL-15, IFN- $\alpha$, anti-ICOS, and anti-CD28 on antigen-specific T cell responses in patients infected with HCV or HIV versus healthy individuals. Our data show that none of the aforementioned molecules could significantly increase ELISPOT sensitivity, neither in HCV nor in HIV. Moreover, all of them caused false-positive responses to HCV and HIV antigens in healthy individuals. Our results question the broad use of in vitro costimulation.

Copyright (C) 2008 Stefanie Kuerten et al. This is an open access article distributed under the Creative Commons Attribution License, which permits unrestricted use, distribution, and reproduction in any medium, provided the original work is properly cited.

\section{INTRODUCTION}

The measurement of immune responses to disease-specific antigens has become increasingly important in chronic viral infections. Particularly T cell responses have proven to be a valuable tool both for vaccine development and immune monitoring $[1,2]$. Examining the phenotype and activation status of T cells (e.g., by FACS analysis) or their cytokine secretion profile (e.g., in ELISPOT assays) not only provides helpful information on the immunogenicity of individual viral antigens, but also reflects the patient's current state of immunocompetence, a vital piece of information for treatment and prognosis.

One major obstacle, however, is the intrinsically lowfrequency and cytokine productivity of $\mathrm{T}$ cells in hosts suffering from chronic disease. Not only infections like HIV that directly impair $\mathrm{T}$ cell function, but also viral infections that target cells outside the immune system, such as $\mathrm{HCV}$, have been shown to decrease $\mathrm{T}$ cell reactivity to viral antigensin vitro [3-10]. As shown by Yonkers et al., this effect is even more pronounced in cases of HIV/HCV coinfection [11]. This alteration of $\mathrm{T}$ cell function by chronic viral infections makes it almost impossible to accurately quantify the disease-specific $\mathrm{T}$ cell repertoire in vitro.

A great deal of hope has therefore been placed into the use of in vitro costimulation. Adding molecules such as agonistic anti-CD28 antibodies or cytokines like IL-7 and IL-15 to FACS and ELISPOT assays is intended to optimize the interaction between T cells and APC [11-13]. The rationale of a strong second signal compensating for a weak first signal and/or a high $\mathrm{T}$ cell activation threshold is indeed appealing. Pathogen-specific T cells would no longer escape detection due to suboptimal in vitro stimulation, but would be reliably activated above threshold and thus become detectable. Following this rationale, in vitro stimulation would allow for a precise quantification of each individual's antigen-specific T cell repertoire.

Several studies have indeed shown increased $\mathrm{T}$ cell responses after in vitro costimulation; Jennes et al. demonstrated that the presence of IL-7 and IL-15 during T cell stimulation in ELISPOT assays significantly increases the frequency of PPD-specific and CMV-specific T cells [12]. 
Calarota et al. later demonstrated that IL-15 alone suffices to enhance IFN- $\gamma$ production to both simian-human immunodeficiency virus and HIV antigens in infected macaques [14]. Finally, Ott et al. demonstrated that agonistic antiCD28 antibody increases the IFN- $\gamma$ response to tetanus toxoid, mumps antigen, CMV, and EBV peptides in healthy individuals as well as responses to NS3 protein in HCV patients and proinsulin along with islet cell antigen in type 1 diabetes patients [13].

Other studies, however, indicate a rather limited effect of in vitro costimulation. As Yonkers et al. demonstrated, memory-effector CD8 cells show reduced responsiveness to CD28 costimulation in $\mathrm{HCV} / \mathrm{HIV}$ coinfection [11]. Subudhi et al. carefully delineated the opposing effects of B7 family members on immune responses, and showed that immune modulators frequently lead to coinhibition rather than the desired stimulation [15].

Much uncertainty therefore remains mainly because no human study to date has systematically compared multiple types of in vitro costimulation in the setting of different viral infections. Moreover, most studies compare stimulated versus unstimulated responses within infected patients. Little attention, however, has so far been paid to the effect of in vitro costimulation in healthy, uninfected individuals. How specific are the responses obtained after costimulation? Is the desired increase in assay sensitivity compromised by decreased specificity?

Our present study sheds some light upon these essential questions. We systematically compared the effects of four different methods of in vitro costimulation: IL-7/IL-15,IFN- $\alpha$, anti-ICOS, and anti-CD28. Using IFN- $\gamma$ ELISPOT assays with and without costimulation, we measured the $\mathrm{T}$ cell response to disease-specific antigens in $10 \mathrm{HCV}$ patients, 10 HIV patients, and 6 healthy individuals. Our results lead to three major conclusions. Firstly, in HCV patients, significant increases in $\mathrm{T}$ cell reactivity could only be seen with one particular antigen (NS3 protein) when using either IL-7/IL15 or anti-CD28. Secondly, in HIV patients, none of the four types of in vitro costimulation led to a statistically significant response increase, regardless of the antigen used. Lastly and most importantly, all four methods of costimulation led to false-positive responses to HCV and HIV antigens in healthy individuals.

\section{MATERIALS AND METHODS}

\subsection{Subjects and sample collection}

Peripheral blood was obtained from $10 \mathrm{HIV}$ positive and $10 \mathrm{HCV}$-infected subjects - the former from the Special Immunology Unit at University Hospitals of Cleveland, and the latter from the Cleveland Veterans Affairs Medical Center and University Hospitals of Cleveland. HIV infection was defined as a positive result for ELISA or other licensed HIV antibody tests, as well as previously detectable plasma HIV RNA. HCV infection was defined as detectable serum HCV antibodies and RNA. The six healthy controls tested were members of our and adjoining laboratories, and were negative for both HIV and HCV antibodies. For all partici- pants, PBMCs were isolated from $40-100 \mathrm{~mL}$ of heparinized blood by standard Ficoll density-gradient centrifugation (IsoPrep, Robbins Scientific Corp., Sunnyvale, Calif, USA) and immediately used for ELISPOT analysis. All studies were performed under the approval of the Institutional Review Board for Human Investigation at the University Hospitals of Cleveland and the Cleveland Veterans Affairs Medical Center.

\subsection{ELISPOT assays and image analysis}

ImmunoSpot plates (Cellular Technology Ltd., Cleveland, Ohio, USA) were coated with IFN- $\gamma$ capture antibody mAb M700A (Endogen, Woburn, Mass, USA) in PBS $(3 \mu \mathrm{g} / \mathrm{mL})$ and placed at $4^{\circ} \mathrm{C}$ overnight. The plates were then blocked with PBS containing 1\% BSA (Sigma-Aldrich, St. Louis, Mo, USA) for 1 hour and washed three times with PBS. Freshly isolated PBMCs were plated in RPMI-1640 (BioWhittaker, Walkersville,Md, USA) supplemented with $100 \mathrm{U} / \mathrm{mL}$ penicillin, $100 \mu \mathrm{g} / \mathrm{mL}$ streptomycin, $2 \mathrm{mM}$ L-glutamine, and $10 \%$ pooled heat-inactivated human $\mathrm{AB}$ serum. For all experiments, $3 \times 10^{5}$ PBMCs were plated per well in the presence or absence of IL-7/IL-15 (final concentration of $5 \mathrm{ng} / \mathrm{mL}$; Cell Sciences, Canton, Mass, USA), IFN- $\alpha$ (final concentration of $1000 \mathrm{U} / \mathrm{mL}$; Biosource, Camarillo, Calif, USA), agonistic anti-ICOS antibody (final concentration of $1 \mu \mathrm{g} / \mathrm{mL}$; eBioscience, San Diego, Calif, USA), or agonistic anti-CD28 antibody (final concentration of $1 \mu \mathrm{g} / \mathrm{mL}$; BD Pharmingen, San Jose, Calif, USA). The following HIV antigen pools were used: Pool 1 (comprised of HIV-1 peptides A0301 pol, A201 pol 2, A24 nef 8, and A201 nef 1), Pool 2 (comprised of HIV-1 peptides A24 gp41, B27 gp120, A301 p17, and A201 nef2), and Pool 3 (comprised of HIV-1 peptides B27 gp41, A201 nef3, B51 nef, and A24 gp120). All peptide pools were used at $10 \mu \mathrm{g} / \mathrm{mL}$. All HIV peptides were obtained from the NIH AIDS Research and Reference Reagent Program, Division of AIDS, NIAID, NIH. Recombinant HCV core NS3 protein was supplied by Chiron (Emeryville, Calif, USA) and used at a concentration of $10 \mu \mathrm{g} / \mathrm{mL}$. A set of 73 MHC class I-restricted $\mathrm{HCV}$ peptides representing portions of the HCV genotype 1 protein sequence, based upon previously described CD8 determinants [16-19], were synthesized by the multipin technique (Chiron, Emeryville, Calif, USA.) and pooled together as a set (Pepset 4, used at $3.4 \mu \mathrm{M}$ ). Phytohemagglutinin (PHA) was used as positive control in all assays, and was obtained from Sigma-Aldrich $(10 \mu \mathrm{g} / \mathrm{mL})$. Negative control wells contained PBMC with a medium in the presence or absence of the costimulatory agents as mentioned above. After 24 hours of incubation at $37^{\circ} \mathrm{C}$ and $7 \% \mathrm{CO}_{2}$, the plates were washed with PBS and PBS/TWEEN, and IFN- $\gamma$ biotinylated detection antibody mAB M701 (Endogen, $2 \mu \mathrm{g} / \mathrm{mL}$ ) was added. The antibody was diluted in PBS containing 1\% BSA and 0.025\% TWEEN (Fisher Scientific International Inc., Hampton, NH, USA). The plates were incubated at $4^{\circ} \mathrm{C}$ overnight. Then they were washed three times with PBS/TWEEN, and subsequently streptavidin-HRP conjugate (DAKO, Carpinteria, Calif, USA) was added at 1/2000 dilution, incubated for 2 hours at room temperature, and removed by washing twice with PBS and PBS/TWEEN. The spots were visualized 
TABLE 1: Clinical characteristics of study subjects. Data are given as means \pm SD, unless otherwise specified. HCV: hepatitis C virus; HIV: human immunodeficiency virus; ALT: alanine aminotransferase; N/A: not applicable.

\begin{tabular}{|c|c|c|c|}
\hline & $\mathrm{HCV}$ & HIV & Healthy \\
\hline \multirow{2}{*}{ Gender } & \multirow{2}{*}{$n=10$ males } & $n=4$ males & $n=4$ males \\
\hline & & $n=6$ females & $n=2$ females \\
\hline Age & $52.75 \pm 2.3$ & $34.8 \pm 5.9$ & $29.6 \pm 3.4$ \\
\hline CD4 cell count, $10^{6}$ cells $/ \mathrm{L}$ & N/A & $451.3 \pm 134.9$ & N/A \\
\hline Plasma HIV RNA level, IU/mL & $0.0 \pm 0.0$ & $8,685.1 \pm 15,122.8$ & $0.0 \pm 0.0$ \\
\hline \multirow{2}{*}{ HCV genotype } & Type $1: n=9$ & \multirow{2}{*}{ N/A } & \multirow{2}{*}{ N/A } \\
\hline & Type $2: n=1$ & & \\
\hline Plasma HCV RNA level, IU/mL & $1,699,275 \pm 1,505,121$ & $0.0 \pm 0.0$ & $0.0 \pm 0.0$ \\
\hline Albumin, g/dL & $3.9 \pm 0.5$ & N/A & N/A \\
\hline ALT, IU/L & $80.3 \pm 67.2$ & N/A & N/A \\
\hline Total bilirubin level, mg/dL & $0.5 \pm 0.3$ & N/A & N/A \\
\hline Platelet count, $10^{3}$ cells $/ \mathrm{mm}^{3}$ & $211.6 \pm 55.8$ & N/A & N/A \\
\hline On treatment & $4 / 10$ & $8 / 10$ & $0 / 10$ \\
\hline
\end{tabular}

by adding HRP substrate 3-amino-9-ethylcarbozole (Pierce, Rockford, Ill, USA). The reaction was stopped by rinsing the plate with distilled water when distinct spots were visible macroscopically. Plates were dried overnight and images of the ELISPOT wells were captured with an ImmunoSpot Series 5 Analyzer (Cellular Technology Ltd.). Image analysis of the ELISPOT results was performed with the ImmunoSpot 5 Analysis Software (Cellular Technology Ltd.).

\subsection{Statistical analysis}

Mann-Whitney rank sum test was calculated using SigmaStat (Version 7; SPSS Inc., San Jose, Calif, USA) to test for significant differences between values obtained with and without the addition of IL-7/IL-15, IFN- $\alpha$, anti-ICOS, or anti-CD28, respectively. A probability value of $P \leq .05$ was considered to be statistically significant.

\section{RESULTS}

\subsection{Characteristics of the study subjects}

The clinical characteristics of the subjects evaluated for HCV- and HIV-specific T cell functions as well as of healthy individuals are listed in Table 1. Age and gender are listed for all subjects. For HCV-infected patients, HCV genotype, plasma HCV RNA levels, and platelet counts are given. Liver function is represented by serum albumin levels, ALT levels, and total bilirubin levels. For HIV-infected patients, CD4 cell counts and plasma HIV RNA levels are listed. The ratio of treated to untreated patients is given for both patient groups.

\subsection{Increased responses to NS3 protein in HCV-infected patients only after in vitro costimulation with IL-7/IL-15 or anti-CD28}

In order to compare the effects of different types of in vitro costimulation in $10 \mathrm{HCV}$-infected patients, we tested recall responses to NS3 protein and Pepset 4 peptide pool in IFN- $\gamma$ ELISPOT assays. Results are shown in Figure 1.

Figure 1(a) illustrates the low baseline responses to NS3 protein and Pepset 4 pool $(2.5 \pm 2.5$ and $6.8 \pm 9.3$ spots above medium, resp.) as frequently described in the literature in the case of chronic infection [3-10]. The presence of IL-7/IL-15 during in vitro $\mathrm{T}$ cell stimulation led to a significant ten-fold upregulation of IFN- $\gamma$ recall responses to NS3 protein (Figure $1(\mathrm{~b}) ; P=.02$ ). Three of the patients also showed increased responses to Pepset 4. However, due to the wide range of spot numbers, the mean increase was not statistically significant. Neither IFN- $\alpha$ (Figure 1(c)) nor anti-ICOS (Figure 1(d)) had a general effect on $\mathrm{HCV}$-specific responses. Only HCV patients 1 and 7 showed an increased NS3 response upon IFN- $\alpha$ stimulation $(P=.002$ and $P=.026$, resp.). Costimulation with antiCD28 (Figure 1(e)) showed similar results compared to IL7/IL-15 with a significant four-fold increase of spot numbers $(P=.021)$ after recall with NS3 protein. This is consistent with observations made by Yonkers et al. and Ott et al. showing that $\mathrm{HCV}$-specific $\mathrm{T}$ cells remain responsive to CD28 stimulation during chronic infection [11, 13]. This consistency of results despite significantly different patient age distributions in the aforementioned studies also shows that patient age does not seem to influence the effects of in vitro costimulation.

\subsection{In vitro costimulation has no effect on antigen-specific $T$ cell responses in HIV-infected patients}

In order to explore whether the aforementioned types of costimulation have a similar effect in the case of HIV infection, we tested recall responses to three different HIV peptide pools in $10 \mathrm{HIV}$-infected patients. Results are shown in Figure 2.

Unlike in $\mathrm{HCV}$, some of the patients showed positive baseline responses to HIV peptides (Figure 2(a)). However, none of the costimulatory reagents could significantly 


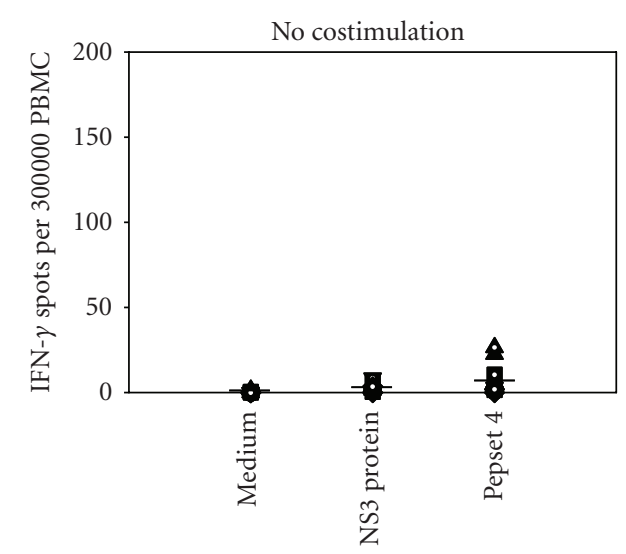

(a)

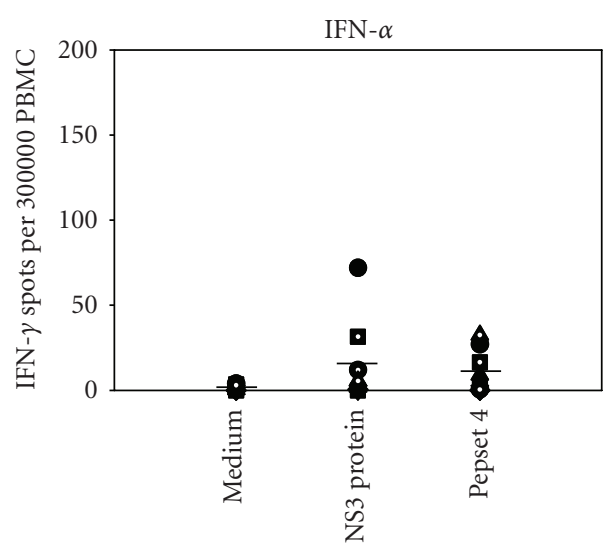

(c)

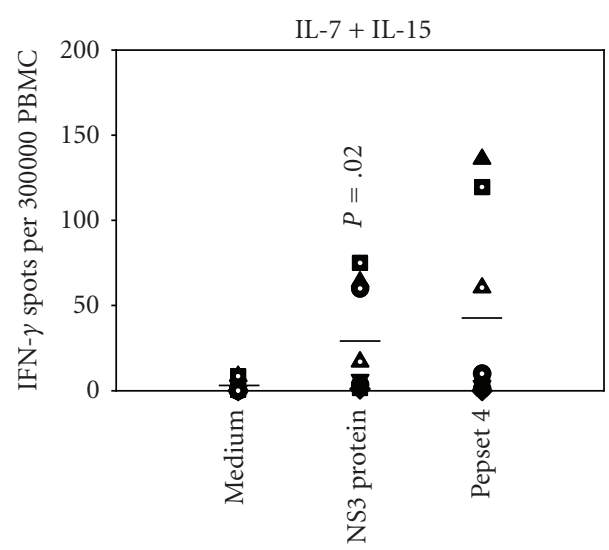

(b)

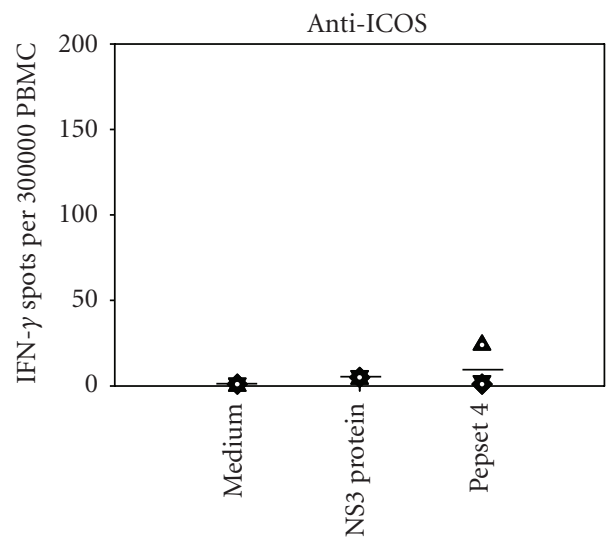

(d)

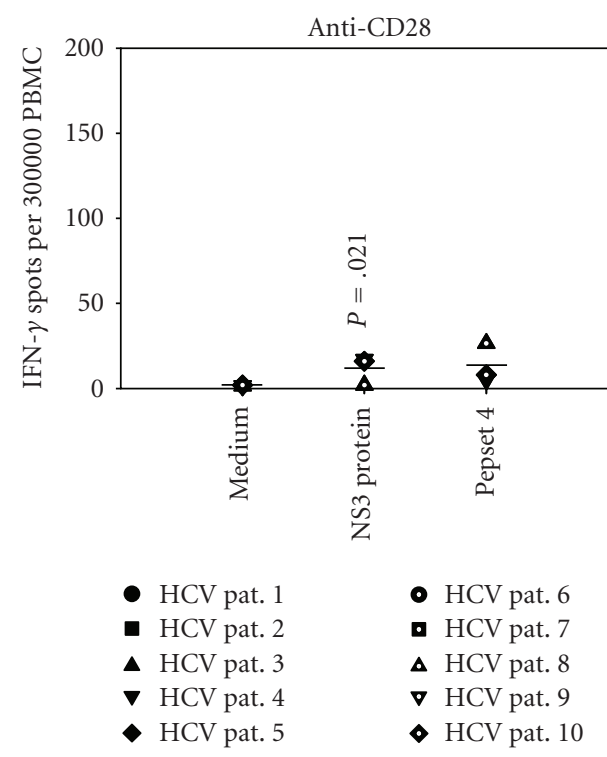

(e)

FIGURE 1: Increased responses to NS3 protein in HCV-infected patients only after in vitro costimulation with IL-7/IL-15 or anti-CD28. PBMCs of $10 \mathrm{HCV}$-infected patients were tested in IFN- $\gamma$ ELISPOT assays for their recall responses to NS3 protein and Pepset 4 peptide pool in the absence (a) or presence of IL-7/IL-15 (b), IFN- $\alpha$ (c), anti-ICOS (d), or CD28 (e). For each individual, the mean spot count of duplicate wells is shown. Horizontal bars indicate the means of all individual responses to the respective antigens. $P$ values are given for means that are significantly different from baseline values in (a). Symbols in (a) also apply to (b)-(e). 
enhance the overall response pattern, as shown in Figures 2(b)-2(e). None of the mean responses to any of the antigens was significantly elevated, regardless of the (interindividually highly variable) baseline reactivity. Results were also identical in both antiretrovirally treated and untreated patients, showing that antiretroviral therapy did not seem to influence the effects of in vitro costimulation. This decreased responsiveness of HIV-infected lymphocytes to costimulation has previously been described by Borthwick et al. [20] and Trimble et al. [21], and is attributed to the downregulation of costimulatory molecules such as CD28 on T cells in the course of chronic HIV infection [22-24]. The precise mechanisms of this defect, however, are still not understood. Our data indicate that this effect may not be limited to CD28.

\subsection{In vitro costimulation causes false-positive $T$ cell responses to HCV and HIV antigens in healthy individuals}

To date, there are no conclusive data available regarding the effect of in vitro costimulation on HCV- and HIV-specific recall responses in healthy individuals. This information is crucial, though, in order to be able to properly interpret positive test results obtained from assays using in vitro costimulation. Therefore, we specifically tested the same HCV and HIV antigens as above in 6 healthy individuals (Figure 3). If in vitro costimulation enhances existing responses without altering disease specificity, it should not induce positive responses in healthy individuals.

As shown in Figure 3, all four methods of in vitro costimulation (Figures 3(b)-3(e)) caused marked responses to HCV and/or HIV antigens in several healthy individuals. IL-7/IL-15 (Figure 3(b)) led to a strong positive response to Pepset 4 peptide pool (twenty-fold increase above baseline; $P=.026$ ) as well as to HIV pool 1 (ten-fold increase above baseline; $P=.030$ ). The mean frequency of NS3 reactive $\mathrm{T}$ cells was increased six-fold. Although this shift in mean frequency is not statistically significant due to the broad range of anti-NS3 responses, the changes for individual subjects are highly significant $(P=.002$ for Healthy Control $1 ; P=.005$ for Healthy Control 2).

Similarly, IFN- $\alpha$ also induced false-positive responses to NS3 (Figure 3(c)), as seen in two individuals $(P=.028$ for Healthy Control $1 ; P=.021$ for Healthy Control 2). Interestingly, these individuals had also displayed susceptibility to IL-7/IL-15 stimulation (Figure 3(b)). In vitro costimulation with anti-ICOS agonist (Figure $3(\mathrm{~d})$ ) upregulated anti-NS3 responses to a lesser degree. Healthy Control 4 responded with $\sim 300$ spots above baseline $(P<.001)$. Remarkably, this individual had previously proven nonreactive to both IL-7/IL-15 and IFN- $\alpha$. The mean frequency of Pepset 4 reactive $\mathrm{T}$ cells increased four-fold $(P=.011)$ upon ICOS stimulation.

Finally, as shown in Figure 3(e), CD28 costimulation also caused false-positive test results. Healthy Control 4 responded to NS3 approximately three-fold above baseline $(P=.006)$. Moreover, mean spot counts for Pepset 4 were also increased significantly $(P=.033)$.

\section{DISCUSSION}

Efforts for in vitro $\mathrm{T}$ cell analysis attempt to establish frequencies of antigen-reactive cells and their effector functions, defined by the release of cytokines secreted upon antigen encounter. Tetramer staining for intracellular cytokines, cytolytic molecules, and antigen-specific $\mathrm{T}$ cell receptors (TCRs) is a technique frequently used for this purpose. It further allows the characterization of cell surface marker expression by antigen-specific cells, distinguishing, for example, between central and effector memory cells or between CD4 and CD8 cells [25].

In many cases, however, there is no true dominance of a particular peptide antigen. This has been described in HIV and recently also in response to vaccinia virus [26]. For this reason, immune diagnostics in infectious diseases is shifting towards the use of peptide pools as antigens. Since this approach is unfeasible in flow cytometry, functional test systems are commonly used for this purpose in which antigen directly activates the $\mathrm{T}$ cells and the resulting cytokine secretion is detected. Cytokines can be measured in the cell supernatant by ELISA or directly around the secreting cell using ELISPOT assays. ELISPOT assays typically are more sensitive compared to ELISA because they are able to detect the cytokine production of each individual cell before the cytokine is diluted into the supernatant, degraded by proteases, or neutralized by receptors of bystander cells. As far as cell frequencies are concerned, ELISPOT essentially provides the same information as intracellular cytokine staining (ICS). However, the detection limit of ELISPOT can be as low as 1/100000 cells, ten times lower than ICS [27]. Moreover, ELISPOT measures the biologically relevant secretion of a cytokine as opposed to its intracellular storage detected by ICS. The intracellular presence of granzyme B or perforin, for example, merely indicates that the cell has encountered antigen within the past month [28]. In contrast, the actual release of granzyme $\mathrm{B}$ or perforin indicates immediate antigen recognition by a specific cell $[1,2]$.

All of these functional assays, however, have one major weakness in common. They provide accurate information on $\mathrm{T}$ cell frequencies and function only if all specific $\mathrm{T}$ cells present in the test cell population undergo full activation. For example, recognition of an antigen presented by a dendritic cell (DC) along with strong costimulation will result in full $\mathrm{T}$ cell activation. This lies in contrast with $\mathrm{T}$ cell activation by $\mathrm{B}$ cells which are known to be cells with rather weak costimulatory capabilities [29]. In the latter case, only a fraction of antigen-specific $\mathrm{T}$ cells will be fully activated. As a consequence, the assay will mainly detect those cells that happen to make contact with a DC instead of a B cell when sedimenting out of single-cell suspension onto the bottom of the test plate. Since DCs are less abundant in peripheral blood than $\mathrm{B}$ cells, the frequencies of antigenspecific $\mathrm{T}$ cells will be considerably underestimated. A T cell would acquire different effector functions depending on the type of APC presenting the antigen, and functional assays would be strongly influenced by the prevalent types of APC populations in the blood. Equally, conditions that lead to APC depletion or inactivation, such as HIV and 


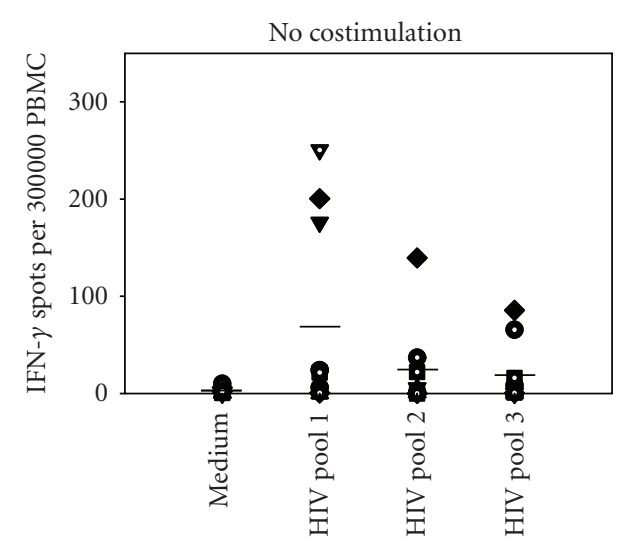

(a)

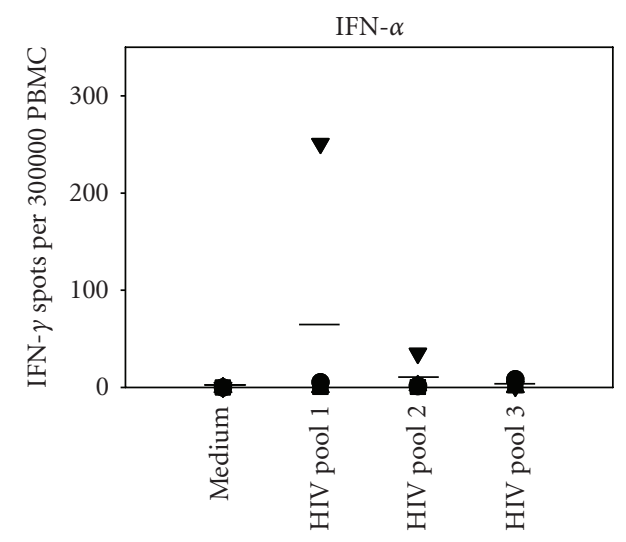

(c)

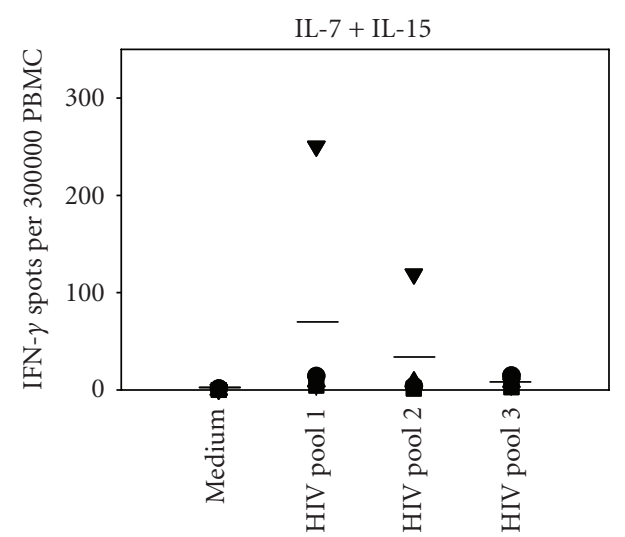

(b)

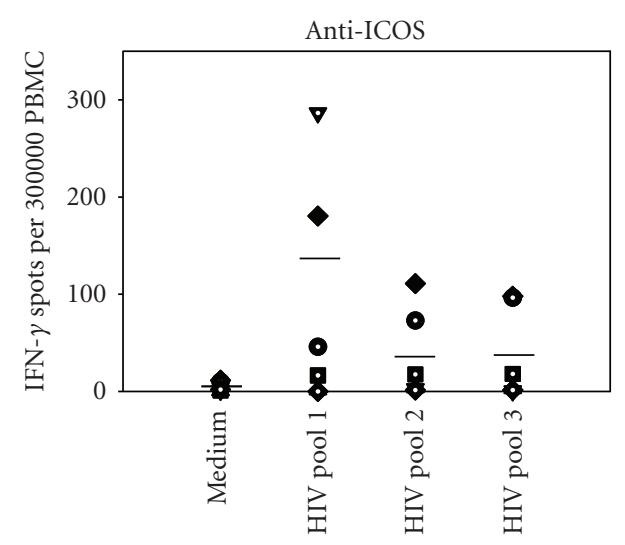

(d)

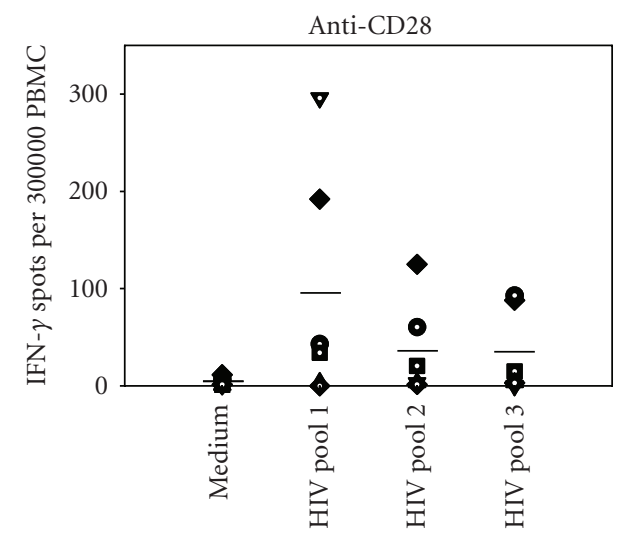

- HIV pat. 1

- HIV pat. 6

- HIV pat. 2 - HIV pat. 7

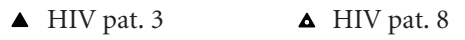

$\boldsymbol{\nabla}$ HIV pat. $4 \quad \boldsymbol{\nabla}$ HIV pat. 9

• HIV pat. 5 HIV pat. 10

(e)

FIgURE 2: In vitro costimulation has no effect on antigen-specific T cell responses in HIV-infected patients. PBMCs of 10 HIV-infected patients were tested in IFN- $\gamma$ ELISPOT assays for their recall responses to HIV peptide pools 1, 2, and 3 (as described in Section 2 ) in the absence (a) or presence of IL-7/IL-15 (b), IFN- $\alpha$ (c), anti-ICOS (d), or CD28 (e). For each individual, the mean spot count of duplicate wells is shown. Horizontal bars indicate the means of all individual responses to the respective antigens. Symbols in (a) also apply to (b)-(e). 


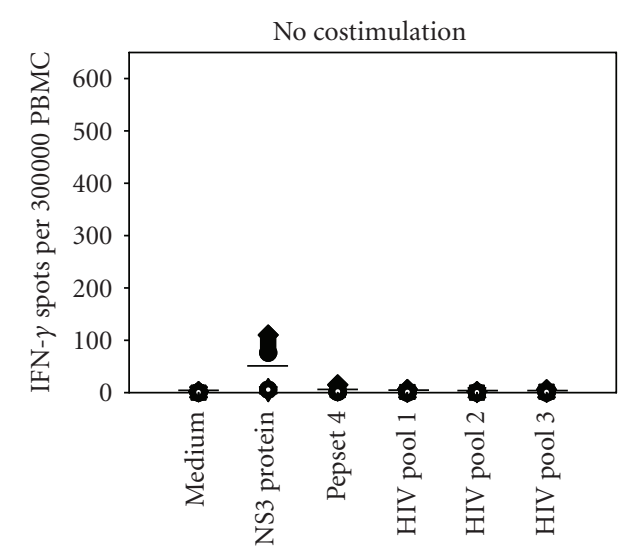

(a)

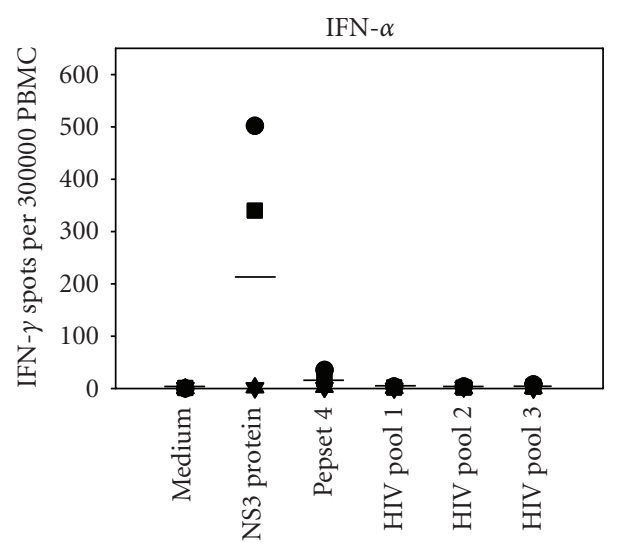

(c)

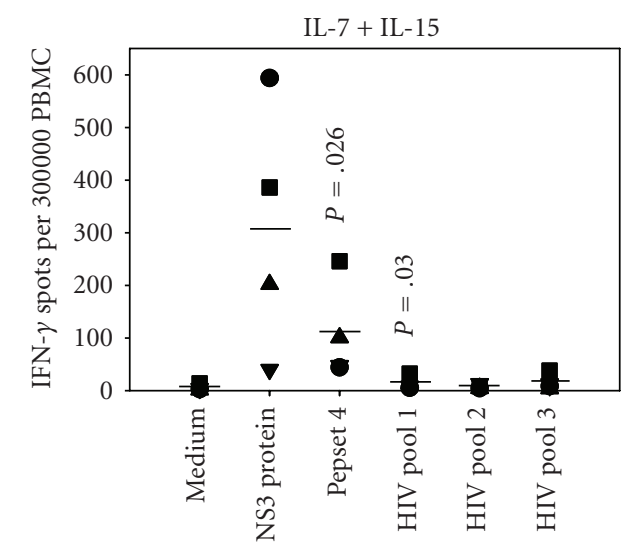

(b)

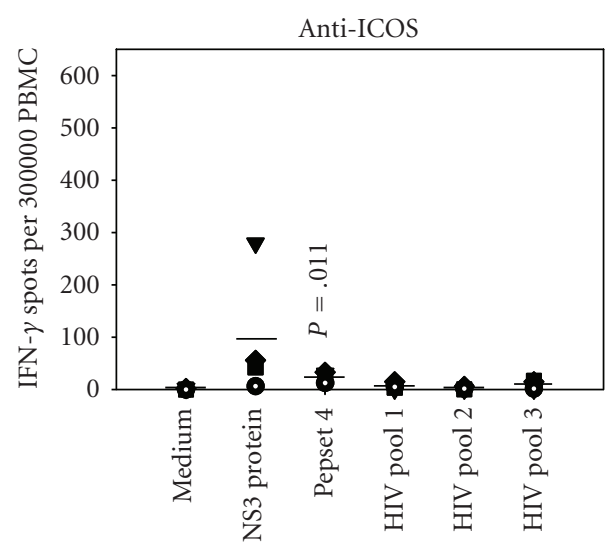

(d)

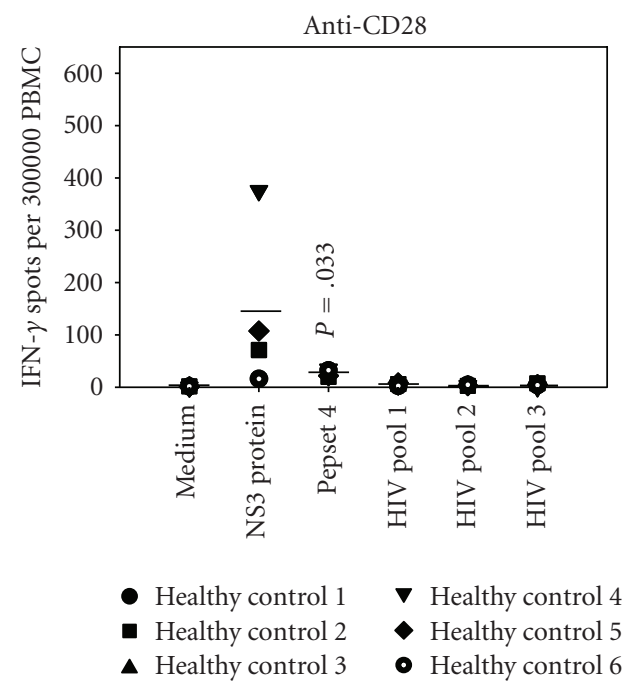

(e)

FIgURe 3: In vitro costimulation causes false-positive T cell responses to HCV and HIV antigens in healthy individuals. PBMCs of 6 healthy individuals were tested in IFN- $\gamma$ ELISPOT assays for their recall responses to NS3 protein, Pepset 4 peptide pool, and HIV peptide pools 1 , 2 , and 3 in the absence (a) or presence of IL-7/IL-15 (b), IFN- $\alpha$ (c), anti-ICOS (d), or CD28 (e). For each individual, the mean spot count of duplicate wells is shown. Horizontal bars indicate the means of all individual responses to the respective antigens. $P$ values are given for means that are significantly different from baseline values in (a). Symbols in (a) also apply to (b)-(e). 
cancer, would leave many antigen-specific T cells undetected, due to the lack of proper stimulation. This is one of the reasons why in chronic diseases such as HIV and HCV it has been notoriously difficult to detect antigen-specific $\mathrm{T}$ cells in significant numbers. Are T cells functionally impaired under such conditions or is their activation hampered by limited numbers of APC? This has not been sufficiently studied yet. For this reason, there have been increasing efforts in the field to include costimulatory signals in $\mathrm{T}$ cell activating cultures in order to overcome the deficiencies of the APC compartment or of the T cells themselves.

A prototypic costimulatory molecule is CD28 [30], the only B7 receptor constitutively expressed on naive $\mathrm{T}$ cells. In addition to ligation of TCR and MHC antigen complex, binding of CD28 to either B7.1 or B7.2 on the APC leads to upregulation of autocrine IL-2 secretion by the T cell. CD28 is commonly used for signal enhancement in flow cytometry. In a previous study, we found that it can also have "signalenhancing" activity on recall responses to tetanus, mumps, CMV, and EBV antigens in healthy individuals.

In the experiments reported here, we extended our previous studies and tested the effects of different types of in vitro costimulation on HCV- and HIV-specific recall responses not only in HCV- and HIV-infected patients, but also in healthy individuals. Strikingly, we found that even in healthy donors anti-CD28 induced significant responses to Pepset 4 antigens in addition to a strong response to NS3 in one donor. While in HCV patients the results were weakly increased for NS3, in HIV patients CD28 costimulation did not result in signal enhancement to any of the antigens tested. Therefore, we conclude that the use of anti-CD28 agonist provides no consistent benefit in either HIV or HCV infection. In vitro costimulation with a combination of antiCD28 and anti-CD49d antibodies led to similar results (data not shown).

We also tested the use of IFN- $\alpha$ as a costimulatory reagent. IFN- $\alpha$ constitutes a "danger signal" released by cells of the innate immune system when infected with virus or upon TLR stimulation [31]. In our study, IFN- $\alpha$ caused false-positive responses to NS3 in two of the healthy donors, while having little to no effect on responses to any of the other antigens. In HIV patients, the antigen-specific recall responses were even reduced in the presence of IFN- $\alpha$ while in HCV patients they were increased to NS3 protein in two of the patients. These data warrant further studies and clearly show that the use of IFN- $\alpha$ for in vitro costimulation can result in false-positive responses in healthy individuals while showing no useful effect in either HCV or HIV infection.

We also tested agonistic anti-ICOS antibody as a costimulatory reagent. Belonging to the CD28 family [30], anti-ICOS showed similar effects to anti-CD28. It did not have significant effects on recall responses in HIV and HCV patients, but caused false-positive responses to NS3 in healthy controls.

The combination of IL-7 and IL-15 has been used in in vitro assays to increase assay sensitivity [12]. Particularly for CD8 memory cells, both cytokines represent growth and differentiation factors. Strikingly, the combination of IL7 and IL-15 induced strong responses in healthy controls to NS3 protein, Pepset 4, and HIV pool 1. Increased "antigen-specific" recall responses to both NS3 and Pepset 4 were also seen in HCV patients. However, in the light of the nonspecific stimulatory effect of IL-7/IL-15 in healthy controls, these responses cannot be interpreted as specific. Finally, similar to IFN- $\alpha$, the combination of IL-7/IL-15 led to a marked reduction of cytokine responses to all three HIV peptide pools in HIV patients. It is unclear why HIVinfected individuals respond so differently compared to $\mathrm{HCV}$ patients and healthy controls. Possible reasons include the reduced $\mathrm{T}$ cell function and susceptibility to costimulation as a consequence of HIV infection as previously described for CD28 [22-24].

\section{CONCLUSION}

Overall, our data show that in vitro costimulation with IL$7 / \mathrm{IL}-15$, IFN- $\alpha$, anti-ICOS, and anti-CD28 is no "magic bullet" providing simple solutions for improved $\mathrm{T}$ cell diagnostics. There are two criteria that a method of in vitro costimulation has to fulfill in order to qualify as clinically and/or scientifically useful, reliably enhancing antigen responses in a disease-specific manner without causing falsepositive responses in healthy individuals. Our results show that essentially none of the stimulatory molecules tested met these criteria. There are two possible interpretations of these results. On the one hand, insufficient costimulation may not be the limiting factor in HCV or HIV patients, which explains why additional costimulation does not help to reveal more specific activity. The other possibility is that the functional defects present in diseases like HIV and HCV are too severe-either on the $\mathrm{T}$ cell or the antigen presentation side- - to be overcome by in vitro costimulation.

\section{ABBREVIATIONS}

AIDS: Acquired immunodeficiency syndrome

APC: $\quad$ Antigen presenting cell

BSA: Bovine serum albumin

CD: $\quad$ Cluster of differentiation

CMV: Cytomegalovirus

DC: Dendritic cell

EBV: $\quad$ Epstein-Barr virus

ELISA: Enzyme-linked immunosorbent assay

ELISPOT: Enzyme-linked immunosorbent spot

FACS: Fluorescent-activated cell sorting

HCV: Hepatitis $\mathrm{C}$ virus

HIV: Human immunodeficiency virus

HRP: Horseradish peroxidase

ICOS: Inducible costimulator

ICS: Intracellular cytokine staining

IFN: Interferon

IL: Interleukin

MHC: Major histocompatibility complex

NS3: $\quad$ Nonstructural HCV protein

PBMC: Peripheral blood mononuclear cell 
PBS: Phosphate-buffered saline

PHA: Phytohemagglutinin

PPD: Purified protein derivative

RNA: Ribonucleic acid

RPMI: Roswell Park Memorial Institute

TCR: T cell receptor.

\section{ACKNOWLEDGMENTS}

This work was supported by NIH Grants no. AI-47756 to M. Tary-Lehmann and no. RES425819 to P. V. Lehmann. S. Kuerten was supported by the Studienstiftung des Deutschen Volkes, the Köln Fortune Programm (University of Cologne,Germany), and the Maria-Pesch-Stiftung, Köln. The authors wish to thank D. D. Anthony for valuable discussions and generously providing HCV patient samples and antigens. Furthermore, they would like to thank R. J. Asaad for valuable discussions and generously providing HIV patient samples. Stefanie Kuerten and Tobias R. Schlingmann contributed equally to this work.

\section{REFERENCES}

[1] S. Kuerten, T. M. Nowacki, T. O. Kleen, R. J. Asaad, P. V. Lehmann, and M. Tary-Lehmann, "Dissociated production of perforin, granzyme $\mathrm{B}$, and IFN- $\gamma$ by HIV-specific $\mathrm{CD} 8^{+}$cells in HIV infection," AIDS Research and Human Retroviruses, vol. 24, no. 1, pp. 62-71, 2008.

[2] T. M. Nowacki, S. Kuerten, W. Zhang, et al., "Granzyme B production distinguishes recently activated $\mathrm{CD}^{+}$memory cells from resting memory cells," Cellular Immunology, vol. 247, no. 1, pp. 36-48, 2007.

[3] N. Alatrakchi, V. Di Martino, V. Thibault, et al., "Decreased frequencies of virus-specific $\mathrm{T}$ helper type 1 cells during interferon alpha plus ribavirin treatment in HIV-hepatitis C virus co-infection," AIDS, vol. 18, no. 1, pp. 121-123, 2004.

[4] D. D. Anthony, N. L. Yonkers, A. B. Post, et al., "Selective impairments in dendritic cell-associated function distinguish hepatitis C virus and HIV infection," The Journal of Immunology, vol. 172, no. 8, pp. 4907-4916, 2004.

[5] N. H. Gruener, F. Lechner, M.-C. Jung, et al., "Sustained dysfunction of antiviral $\mathrm{CD}^{+} \mathrm{T}$ lymphocytes after infection with hepatitis C virus," Journal of Virology, vol. 75, no. 12, pp. 5550-5558, 2001.

[6] A. Y. Kim, G. M. Lauer, K. Ouchi, et al., "The magnitude and breadth of hepatitis $\mathrm{C}$ virus-specific $\mathrm{CD}^{+} \mathrm{T}$ cells depend on absolute $\mathrm{CD} 4^{+} \mathrm{T}$-cell count in individuals coinfected with HIV-1," Blood, vol. 105, no. 3, pp. 1170-1178, 2005.

[7] G. M. Lauer, T. N. Nguyen, C. L. Day, et al., "Human immunodeficiency virus type 1 -hepatitis $\mathrm{C}$ virus coinfection: intraindividual comparison of cellular immune responses against two persistent viruses," Journal of Virology, vol. 76, no. 6, pp. 2817-2826, 2002.

[8] H. Valdez, D. Anthony, F. Farukhi, et al., "Immune responses to hepatitis $\mathrm{C}$ and non-hepatitis $\mathrm{C}$ antigens in hepatitis $\mathrm{C}$ virus infected and HIV-1 coinfected patients," AIDS, vol. 14, no. 15, pp. 2239-2246, 2000.

[9] H. Valdez, N. L. Carlson, A. B. Post, et al., "HIV long-term non-progressors maintain brisk CD8 $\mathrm{T}$ cell responses to other viral antigens," AIDS, vol. 16, no. 8, pp. 1113-1118, 2002.

[10] H. Wedemeyer, X.-S. He, M. Nascimbeni, et al., "Impaired effector function of hepatitis $\mathrm{C}$ virus-specific $\mathrm{CD}^{+} \mathrm{T}$ cells in chronic hepatitis C virus infection," The Journal of Immunology, vol. 169, no. 6, pp. 3447-3458, 2002.

[11] N. L. Yonkers, B. Rodriguez, A. B. Post, et al., "HIV coinfection impairs CD28-mediated costimulation of hepatitis C virusspecific CD8 cells," The Journal of Infectious Diseases, vol. 194, no. 3, pp. 391-400, 2006.

[12] W. Jennes, L. Kestens, D. F. Nixon, and B. L. Shacklett, "Enhanced ELISPOT detection of antigen-specific $\mathrm{T}$ cell responses from cryopreserved specimens with addition of both IL-7 and IL-15-the Amplispot assay," Journal of Immunological Methods, vol. 270, no. 1, pp. 99-108, 2002.

[13] P. A. Ott, B. R. Berner, B. A. Herzog, et al., "CD28 costimulation enhances the sensitivity of the ELISPOT assay for detection of antigen-specific memory effector CD4 and CD8 cell populations in human diseases," Journal of Immunological Methods, vol. 285, no. 2, pp. 223-235, 2004.

[14] S. A. Calarota, M. Otero, K. Hermanstayne, et al., "Use of interleukin 15 to enhance interferon- $\gamma$ production by antigenspecific stimulated lymphocytes from rhesus macaques," Journal of Immunological Methods, vol. 279, no. 1-2, pp. 55-67, 2003.

[15] S. K. Subudhi, M.-L. Alegre, and Y.-X. Fu, "The balance of immune responses: costimulation verse coinhibition," Journal of Molecular Medicine, vol. 83, no. 3, pp. 193-202, 2005.

[16] K.-M. Chang, N. H. Gruener, S. Southwood, et al., "Identification of HLA-A3 and -B7-restricted CTL response to hepatitis $\mathrm{C}$ virus in patients with acute and chronic hepatitis C," The Journal of Immunology, vol. 162, no. 2, pp. 1156-1164, 1999.

[17] M. J. Koziel, "The role of immune responses in the pathogenesis of hepatitis C virus infection," Journal of Viral Hepatitis, vol. 4, supplement 2, pp. 31-41, 1997.

[18] P. Scognamiglio, D. Accapezzato, M. A. Casciaro, et al., "Presence of effector $\mathrm{CD}^{+} \mathrm{T}$ cells in hepatitis $\mathrm{C}$ virus-exposed healthy seronegative donors," The Journal of Immunology, vol. 162, no. 11, pp. 6681-6689, 1999.

[19] D. K. H. Wong, D. D. Dudley, N. H. Afdhal, et al., "Liverderived CTL in hepatitis $\mathrm{C}$ virus infection: breadth and specificity of responses in a cohort of persons with chronic infection," The Journal of Immunology, vol. 160, no. 3, pp. 1479-1488, 1998.

[20] N. J. Borthwick, M. Bofill, W. M. Gombert, et al., "Lymphocyte activation in HIV-1 infection. II. Functional defects of CD28T cells," AIDS, vol. 8, no. 4, pp. 431-441, 1994.

[21] L. A. Trimble, P. Shankar, M. Patterson, J. P. Daily, and J. Lieberman, "Human immunodeficiency virus-specific circulating CD8 T lymphocytes have down-modulated $\mathrm{CD} 3 \zeta$ and CD28, key signaling molecules for T-cell activation," Journal of Virology, vol. 74, no. 16, pp. 7320-7330, 2000.

[22] J. Gamberg, I. Pardoe, M. I. Bowmer, C. Howley, and M. Grant, "Lack of CD28 expression on HIV-specific cytotoxic T lymphocytes is associated with disease progression," Immunology \& Cell Biology, vol. 82, no. 1, pp. 38-46, 2004.

[23] R. Kämmerer, A. Iten, P. C. Frei, and P. Bürgisser, "Expansion of T cells negative for CD28 expression in HIV infection. Relation to activation markers and cell adhesion molecules, and correlation with prognostic markers," Medical Microbiology and Immunology, vol. 185, no. 1, pp. 19-25, 1996.

[24] S. R. Ostrowski, J. Gerstoft, B. K. Pedersen, and H. Ullum, "A low level of $\mathrm{CD} 4{ }^{+} \mathrm{CD} 28^{+} \mathrm{T}$ cells is an independent predictor of high mortality in human immunodeficiency virus type 1infected patients," The Journal of Infectious Diseases, vol. 187, no. 11, pp. 1726-1734, 2003.

[25] S. S. Vollers and L. J. Stern, "Class II major histocompatibility complex tetramer staining: progress, problems, and prospects," Immunology, vol. 123, no. 3, pp. 305-313, 2008. 
[26] E. Assarsson, J. Sidney, C. Oseroff, et al., "A quantitative analysis of the variables affecting the repertoire of $\mathrm{T}$ cell specificities recognized after vaccinia virus infection," The Journal of Immunology, vol. 178, no. 12, pp. 7890-7901, 2007.

[27] A. Y. Karulin, M. D. Hesse, M. Tary-Lehmann, and P. V. Lehmann, "Single-cytokine-producing CD4 memory cells predominate in type 1 and type 2 immunity," The Journal of Immunology, vol. 164, no. 4, pp. 1862-1872, 2000.

[28] M. T. Rock, S. M. Yoder, P. F. Wright, T. R. Talbot, K. M. Edwards, and J. E. Crowe Jr., "Differential regulation of granzyme and perforin in effector and memory T cells following smallpox immunization," The Journal of Immunology, vol. 174, no. 6, pp. 3757-3764, 2005.

[29] I. S. Grewal and R. A. Flavell, "The role of CD40 ligand in costimulation and T-cell activation," Immunological Reviews, vol. 153, pp. 85-106, 1996.

[30] B. M. Carreno and M. Collins, "The B7 family of ligands and its receptors: new pathways for costimulation and inhibition of immune responses," Annual Review of Immunology, vol. 20, pp. 29-53, 2002.

[31] R. M. Roberts, L. Liu, Q. Guo, D. Leaman, and J. Bixby, “The evolution of the type I interferons," Journal of Interferon \& Cytokine Research, vol. 18, no. 10, pp. 805-816, 1998. 


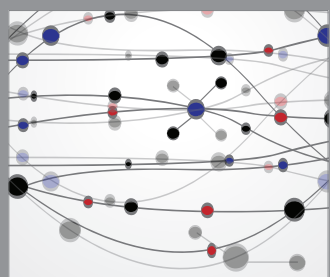

The Scientific World Journal
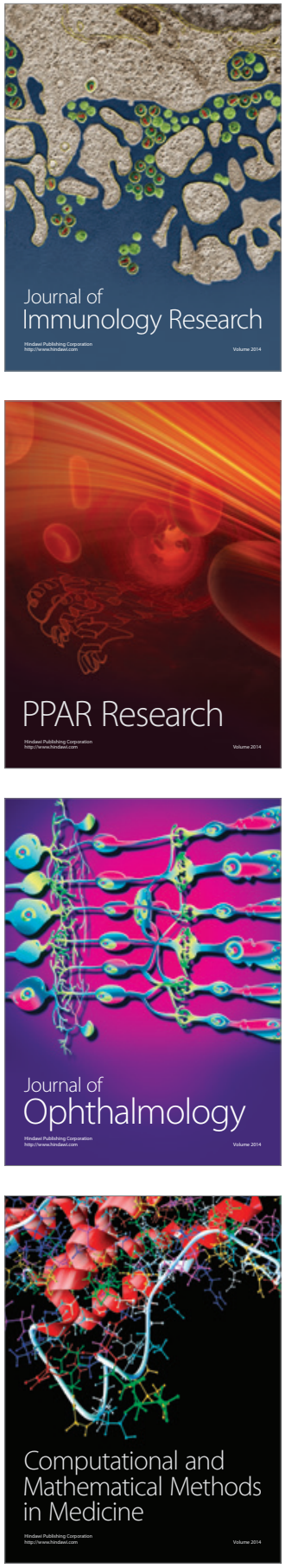

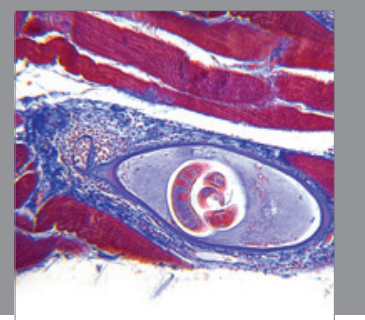

Gastroenterology

Research and Practice
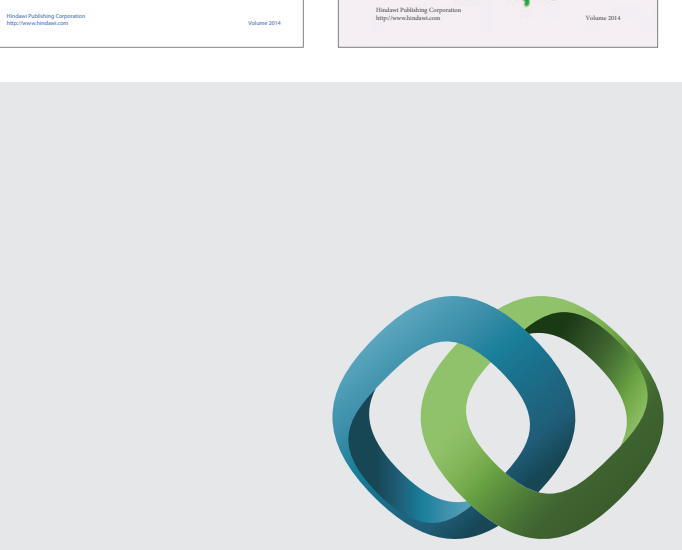

\section{Hindawi}

Submit your manuscripts at

http://www.hindawi.com
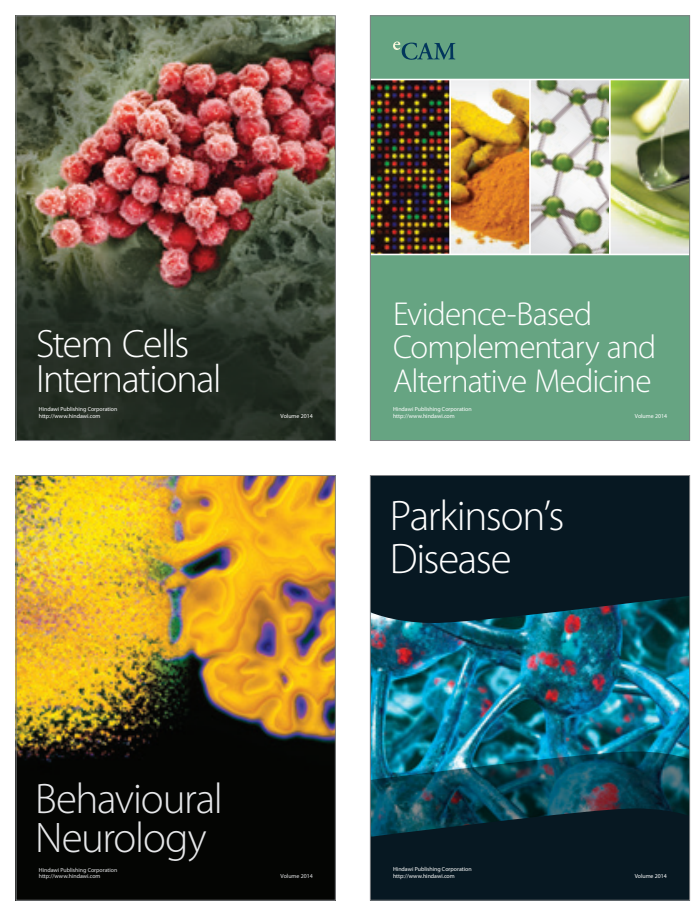

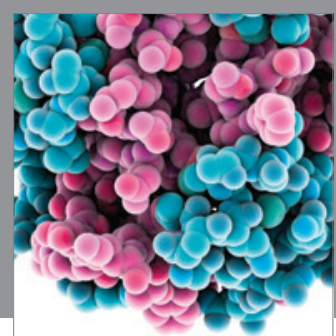

Journal of
Diabetes Research

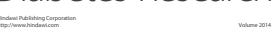

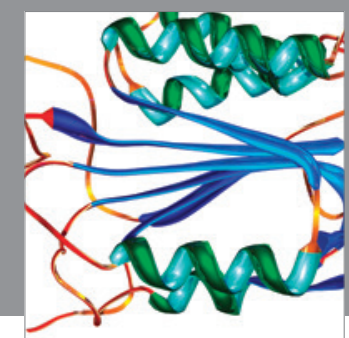

Disease Markers
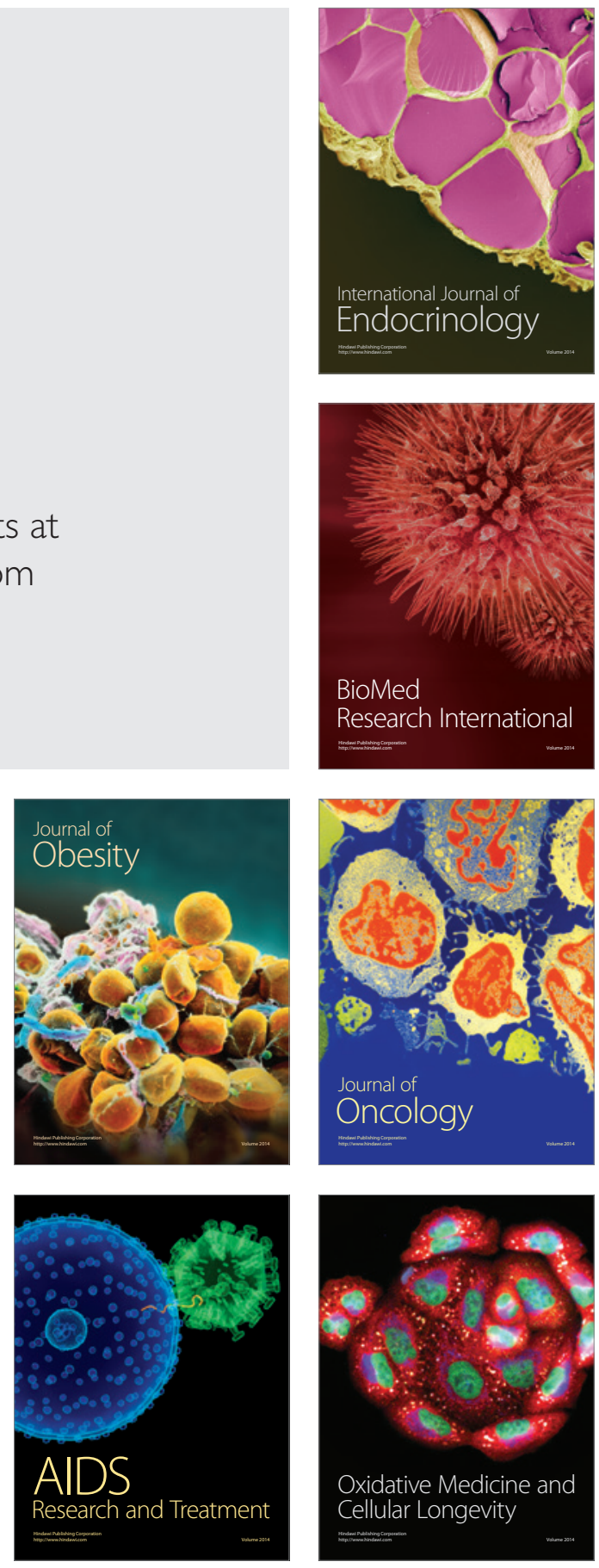